\title{
(6) OPEN ACCESS \\ Adverse consequences of article 12 of the UN Convention on the Rights of Persons with Disabilities for persons with mental disabilities and an alternative way forward
}

\author{
Matthé Scholten, ${ }^{1}$ Jakov Gather ${ }^{1,2}$
}

${ }^{1}$ Institute for Medical Ethics and History of Medicine, Ruhr University Bochum, Bochum, Germany

${ }^{2}$ Department of Psychiatry, Psychotherapy and Preventive Medicine, LWL University Hospital, Ruhr University Bochum, Bochum, Germany

\section{Correspondence to} Dr Matthé Scholten, Institute for Medical Ethics and History of Medicine, Ruhr University Bochum, Bochum 44799, Germany;

matthe.scholten@rub.de

Received 2 June 2017 Revised 21 July 2017 Accepted 24 September 2017 Published Online First 25 October 2017

Check for updates

To cite: Scholten $\mathrm{M}$, Gather J. J Med Ethics 2018:44:226-233.

\begin{abstract}
It is widely accepted among medical ethicists that competence is a necessary condition for informed consent. In this view, if a patient is incompetent to make a particular treatment decision, the decision must be based on an advance directive or made by a substitute decision-maker on behalf of the patient. We call this the competence model. According to a recent report of the United Nations (UN) High Commissioner for Human Rights, article 12 of the UN Convention on the Rights of Persons with Disabilities (CRPD) presents a wholesale rejection of the competence model. The High Commissioner here adopts the interpretation of article 12 proposed by the Committee on the Rights of Persons with Disabilities. On this interpretation, CRPD article 12 renders it impermissible to deny persons with mental disabilities the right to make treatment decisions on the basis of impaired decision-making capacity and demands the replacement of all regimes of substitute decisionmaking by supported decision-making. In this paper, we explicate six adverse consequences of CRPD article 12 for persons with mental disabilities and propose an alternative way forward. The proposed model combines the strengths of the competence model and supported decision-making.
\end{abstract}

\section{INTRODUCTION}

The United Nations (UN) Convention on the Rights of Persons with Disabilities (CRPD) was adopted by the UN General Assembly in 2006 and entered into force in 2008. As of July 2017, 174 states have ratified the convention. ${ }^{1}$ Article 12 CRPD is contentious. According to a recent report on mental health and human rights prepared by the UN High Commissioner for Human Rights, the article entails that 'states should repeal legal frameworks allowing substitute decision-makers to provide consent on behalf of persons with disabilities and introduce supported decision-making'. ${ }^{2}$ The High Commissioner here adopts the interpretation of the article proposed by the Committee on the Rights of Persons with Disabilities (the Committee). In its General Comment on article 12, the Committee likewise claims that 'States parties have an obligation not to permit substitute decision-makers to provide consent on behalf of persons with disabilities' and an 'obligation to replace substitute decision-making regimes by supported decision-making. ${ }^{3}$

This article focuses on the consequences of CRPD article 12 for persons with psychosocial or mental disabilities. For ease of exposition, we will henceforth use the term 'mental disabilities', recognising that mental disabilities are partly constituted by social circumstances. Mental disability is understood as a broad concept that includes mental disorders, neurodevelopmental and neurodegenerative disorders, organic brain damage, learning disabilities and intellectual disability insofar as these conditions in conjunction with the actual social circumstances entail a substantial impairment in functioning. We will focus on conditions that involve shorter or longer periods of impaired decision-making capacity (DMC) followed or preceded by periods of unimpaired DMC, as is the case in, for example, schizophrenia, bipolar disorder, depression and dementia. However, we believe that our conclusions can be generalised to other forms of mental disability.

Reactions to article 12 range from unqualified enthusiasm to strong disapproval. While disability advocates and theorists tend to see the article as the key to the emancipation of persons with mental disabilities, ${ }^{45}$ psychiatrists have voiced the opinion that its provisions will make many persons with mental disabilities worse off. ${ }^{67}$ Others pass moderate criticism on the article or confine themselves to delineating how its provisions could be implemented within their local jurisdictions. ${ }^{8-15}$

According to its first article, the CRPD aims to guarantee the human rights, promote the autonomy, ensure equal treatment and counteract discrimination of persons with disabilities. ${ }^{16}$ While we wholeheartedly embrace the CRPD's principal aims, we contest that the provisions of CRPD article 12 are conducive to the realisation of these aims. In this article, we identify six adverse consequences of CRPD article 12 for persons with mental disabilities and propose an alternative way forward. The model we propose combines the strengths of the competence model and supported decision-making (SDM).

The article is structured as follows. In the section "The competence model", we briefly outline what we will call the competence model. The section “CRPD article 12" lays out the Committee's interpretation of CRPD article 12 and shows that on this interpretation the article presents a wholesale rejection of this model. We point out six adverse consequences of CRPD article 12 for persons with mental disabilities in the section "Adverse consequences of article 12 for persons with mental disabilities". In the section "A combined model: decision-support 
and competence assessment", we propose an alternative model on which these consequences can be averted.

Before we start, a brief note on the interpretation of article 12 is in order. Since failure to comply with human rights documents might lead to reputation damage, governments may feel tempted to interpret the CRPD in such a way that it does not challenge the guardianship and mental health laws of their jurisdiction. The initial reports of Tunisia and Spain provide telling examples, ${ }^{17}$ but similar considerations hold for countries such as the $\mathrm{UK}^{10}$ and Germany. ${ }^{18}$ Academics may feel similarly tempted. Several proponents of the competence model have argued that their theoretical position is in accordance with what they take to be the best interpretation of CRPD article $12 .{ }^{14}{ }^{19}{ }^{20}$ We will not pursue this strategy because it tends to obscure important disagreements. To avoid turning a substantial disagreement into a philological dispute, we will follow the interpretation of article 12 accepted by the Committee and the UN High Commissioner for Human Rights.

\section{THE COMPETENCE MODEL}

On the received model of informed consent, competence is a necessary condition for informed consent. We refer to this model as the competence model. Although it is possible to make further distinctions, ${ }^{21}$ a widely accepted account of the conditions for informed consent in the context of clinical treatment is as follows:

A person gives informed consent to intervention $x$ if, and only if,

1. the relevant information regarding $x$ is adequately disclosed to the person;

2. the person is competent to consent to $x$;

3. the person can voluntarily consent to $x$;

4. the person consents to $x$.

For each of these conditions, one can in turn provide more detailed criteria, and we will say more about the criteria for competence in the section A combined model: decision-support and competence assessment". As is clear from the above, each of these conditions is necessary and together they are sufficient for informed consent. We assume that the same conditions hold for informed treatment rejection.

The conditions listed above must be satisfied for the patient's treatment choice to amount to a 'meaningful choice'22 that entails an 'autonomous authorisation'. ${ }^{21}$ To be more precise, if the conditions for informed consent are satisfied, one's consent to a particular treatment renders proceeding with the treatment permissible, where doing so would otherwise be disallowed. Lawyers and legal scholars express this by saying that one's consent to a medical intervention involves an exercise of legal capacity. Similar considerations hold for treatment rejection. If a competent and informed patient voluntarily rejects a treatment, health professionals are under an obligation respect this choice even if they believe that the choice will have detrimental effects on the patient's well-being. On the other hand, if the requirements for informed consent are not met, a patient's treatment choice does not count as an autonomous authorisation or rejection of the treatment.

If despite reasonable efforts to enhance a patient's competence a patient remains incompetent to make a meaningful treatment decision, her informed consent to (or rejection of) the treatment cannot be obtained. Treatment decisions that are urgent and unavoidable must then be made in a different way. This is where various forms of substitute decision-making come into play.
The various forms of substitute decision-making come in a prioritised list. Advance directives are first on the list. Advance directives are written documents in which persons proclaim their treatment choices and preferences for future situations of incompetence. Even if advance directives may not carry the same authority as the informed and voluntary treatment choices of competent persons, it is commonly accepted that in the absence of strong countervailing reasons they must be respected.

If a valid advance directive is unavailable, the treatment decision must be made by a substitute decision-maker on behalf of the patient. A substitute decision-maker will typically be a (close) relative or friend, ideally appointed by the patient herself; but if a social network is lacking, a legal guardian or alternatively the court can take up this role. Only when neither an advance directive nor an appointed substitute decision-maker can be consulted, as is sometimes the case in emergency situations, health professionals assume the role of substitute decision-maker.

Although there are considerable variations across jurisdictions, the standards for substitute decision-making are roughly as follows. In most jurisdictions, substitute decision-makers should in the first place abide by the treatment preferences that the patient expressed previously at a time when she was competent. If the patient did not express such preferences, the substitute decision-maker should decide on the basis of the so-called substituted judgement standard. According to this standard, the substitute decision-maker should choose the treatment option that the patient would have chosen if she were competent. Finally, if it proofs to be impossible to ascertain what a patient would have chosen in such a hypothetical situation, the substitute decision-maker should make a treatment choice on the basis of the best interest standard. While this standard used to be interpreted as prescribing the treatment with the best medical prognosis, nowadays it is interpreted in a more patient-centred and holistic way, taking into account the patient's values as well as constituents of wellbeing besides medical health.

\section{CRPD ARTICLE 12}

On the interpretation accepted by the Committee and the High Commissioner, CRPD article 12 presents a wholesale rejection of the competence model. We will delineate this interpretation here. The first paragraph of article 12 runs as follows:

1. States parties reaffirm that persons with disabilities have the right to recognition everywhere as persons before the law. ${ }^{16}$

To see the import of this paragraph, we must consider what counts as a disability. Article 1 CRPD gives the following specification: 'Persons with disabilities include those who have longterm physical, mental, intellectual or sensory impairments which in interaction with various barriers may hinder their full and effective participation in society on an equal basis with others'. ${ }^{16}$ Even if much of the CRPD seems tailored to persons with physical or sensory disabilities, this definition thus explicitly includes persons with mental disabilities. Szmukler et al ${ }^{19}$ interpret the qualification 'long-term' as ruling out mental disorders that typically involve only relatively short periods of disability followed by longer periods of remission, such as schizophrenia and bipolar disorder, yet the Committee's comments unmistakably make clear that the definition includes disorders of this type. ${ }^{4}$ 
While the first paragraph of article 12 seems uncontroversial, the second is contentious:

2. States parties shall recognise that persons with disabilities enjoy legal capacity on an equal basis with others in all aspects of life. ${ }^{16}$

A brief elaboration of the notion of legal capacity is in order. The Committee stresses that legal capacity comprises both the capacity to hold rights (legal standing) and the capacity to be an actor under the law (legal agency), explaining that while legal standing 'entitles a person to full protection of his or her rights by the legal system', legal agency licenses a person to 'engage in transactions and create, modify or end legal relationships. ${ }^{3}$ As we have shown in the previous section, by making informed treatment choices one exercises legal agency. This means that the right to make one's own healthcare decisions is an essential element of legal capacity. The second paragraph of article 12 accordingly obliges states parties to recognise that persons with mental disabilities have the right to make their own healthcare decisions.

The scope of this right remains to be determined. Proponents of the competence model have argued that the paragraph does not prohibit denying persons the right to make treatment decisions on the basis of impaired DMC, because the construct of DMC is essentially disability neutral. ${ }^{19} 20$ The Committee decisively denounces this strategy and asserts that 'all persons, regardless of disability or decision-making skills, inherently possess legal capacity'. ${ }^{3}$ As Richardson puts it, the point of the paragraph on this interpretation is precisely that 'legal capacity should not depend on mental capacity'. ${ }^{11}$

The Committee holds that the recognition of legal capacity should be absolute. 'At all times, including in crisis situations', the Committee tellingly explains, 'the individual autonomy and capacity of persons with disabilities to make decisions must be respected'. While acknowledging that persons with disabilities may make unwise treatment decisions in crisis situations, the Committee insists that persons with mental disabilities, too, have 'the right to make mistakes'. ${ }^{3}$ Richardson once more puts the point of this interpretation clearly: 'there is no point beyond which (legal) capacity is lost'. ${ }^{11}$

All forms of substitute decision-making presuppose that the person on whose behalf a treatment decision is made cannot exercise legal agency. The absolute ban on denying legal capacity therefore entails that all regimes of substitute decision-making must be abolished. In its concluding observations on the initial reports of a large range of countries, the Committee therefore again and again repeats that states parties must 'take immediate steps to replace substituted decision-making with supported decision-making'. ${ }^{23}$

The third paragraph of article 12 announces this 'paradigm shift ${ }^{3}$ from substitute decision-making to SDM:

3. States parties shall take appropriate measures to provide access by persons with disabilities to the support they may require in exercising their legal capacity. ${ }^{16}$

The CRPD recognises that persons with disabilities may have difficulties in exercising legal agency. In accordance with the demand for reasonable accommodation expressed in CRPD article $5.3,{ }^{16}$ decision-support must be provided in such cases. Decision-support can be provided by relatives, friends, peers or health professionals. We should be careful not to conflate SDM with substitute decision-making. Rather than determining what the patient would decide if she were competent (substituted judgement standard) or what would be in the best interest of the person (best interest standard), the role of the support person is to help the person with mental disability to articulate her current will and preferences. As the Committee puts it, 'support in the exercise of legal capacity must respect the rights, will and preferences of persons with disabilities and should never amount to substitute decision-making, ${ }^{3}$

In rather ambivalent phrasing, the fourth paragraph of article 12 introduces various safeguards related to the exercise of legal capacity:

4. States parties shall ensure that all measures that relate to the exercise of legal capacity provide for appropriate and effective safeguards to prevent abuse in accordance with international human rights law. Such safeguards shall ensure that measures relating to the exercise of legal capacity respect the rights, will and preferences of the person, are free of conflict of interest and undue influence, are proportional and tailored to the person's circumstances, apply for the shortest time possible and are subject to regular review by a competent, independent and impartial authority or judicial body. The safeguards shall be proportional to the degree to which such measures affect the person's rights and interests. ${ }^{16}$

Understandably, some scholars have interpreted these safeguards as referring to modes of substitute decision-making that should kick in when decision-support proves to be of no avail. ${ }^{11}{ }^{19}$ Yet the Committee makes clear that these safeguards exclusively refer to measures against undue influence. ${ }^{3}$ Instead of allowing for the application of the substituted judgement or best interest standard, it explains, 'the primary purpose of these safeguards must be to ensure the respect of the person's rights, will and preferences'. ${ }^{3}$

The fifth and final paragraph of article 12 concerns the right of persons with disabilities to own property and to manage their financial affairs. Since our focus is on healthcare decisions, we will not elaborate on this paragraph.

To wrap up, on the Committee's interpretation, article 12 CRPD renders it impermissible to deny the right to make treatment decisions to persons with mental disabilities and requires states to replace substitute decision-making with SDM. We will henceforth refer to this model as the exclusive SDM model.

In Canada, Bach and Kerzner ${ }^{8}$ have developed a less radical SDM model in response to CRPD article 12. Like the Committee, Bach and Kerzner hold that persons retain legal capacity even if their DMC falls below the threshold determined by the competence model. In contrast to the Committee, however, they specify a 'minimum threshold for exercising legal capacity'. This threshold is met if

an individual can act in a way that at least one other person who has personal knowledge of the individual can reasonably ascribe to the individual's actions, personal will and/or intentions consistent with the person's identity; and can take reasonable consequential actions to give effect to the will and/or intentions of the individual. ${ }^{8}$

Since on this model one must respect the current will and preferences of persons who meet the threshold for exercising legal capacity yet fail to meet the relevant threshold of DMC, the problems that we identify in the following section will also hold for Bach and Kerzner's SDM model. For practical purposes, however, we will focus on the exclusive SDM model.

\section{ADVERSE CONSEQUENCES OF ARTICLE 12 FOR PERSONS WITH MENTAL DISABILITIES}

While we fully embrace the CRPD's principle aims of promoting the autonomy, ensuring equal treatment and counteracting 
discrimination of persons with disabilities, we contest that the provisions of article 12 contribute to the realisation of these aims. In this section, we identify six adverse consequences of CRPD article 12 for persons with mental disabilities.

The first two adverse consequences are best discussed in conjunction. Article $12 \mathrm{CRPD}$ will in a considerable range of cases have an adverse effect first on the well-being and second on the autonomy of persons with mental disabilities. Because we cannot defend an account of autonomy and well-being in the context of this article, we propose as working assumptions that autonomy consists in having the ability to live one's life according to one's own conception of the good and that wellbeing consists in one's overall experience of happiness or the overall satisfaction of one's desires over an extended period of time. The details are inessential here. What is important is that autonomy is more than simply having the ability to do what one wants at a given point of time; and similarly that well-being is more than merely one's present experience of happiness or the satisfaction of one's present desires.

The point of the practice of informed consent is to protect both our interest in autonomy and our interest in well-being. It protects the latter interest by recognising that patients are normally in the best position to determine which treatment alternative will best promote their well-being; and it protects the former interest by enabling patients to shape their life according to their own conception of the good. When a person's DMC is substantially impaired, however, the person is often not in the best position to assess which treatment option will be most conducive to her well-being and consistent with her conception of the good. In such cases, the practice of informed consent loses its point.

As an illustration of this, consider a person who suffers from a severe psychotic episode. In many such cases, there is little reason to think that unreservedly respecting the person's current treatment choices will protect or further her interest in either autonomy or well-being. Quite the contrary, these interests will often be set back by doing so. Laws that require health professionals to respect treatment rejections by persons with substantially impaired DMC will adversely affect the well-being and autonomy of these persons, because these laws will expose them to risks they would not accept had they been competent and compromise their ability to live a life according to their own conception of the good.

A third adverse consequence of CRPD article 12 is that the exclusive SDM model aggravates the problem of undue influence. This worry is often raised in the literature. ${ }^{24-26}$ It is a well-known fact that families and friendships are not always harmonious and that even relatives and friends with good intentions may in good faith unconsciously project their own interests onto those of the patient. While this is a familiar challenge in substitute decision-making, the problem is aggravated on the exclusive SDM model. Difficult as it may be to apply the substituted judgement standard correctly, it will typically be no easier to discern the current will and preferences of persons with substantially impaired DMC, not in the least because the expressed preferences of these persons are typically diffuse and tend to fluctuate over time. As Craigie puts it, providing decision-support involves the extremely difficult task of finding 'a fine balance of facilitating self-expression without compromising decision-making freedom', ${ }^{26}$ and in many cases this task will turn out to be impracticable.

Although the problem of undue influence affects both the competence model and the exclusive SDM model, the problem is more serious on the latter. We must first remove a potential misunderstanding. It may seem as if the main difference between the exclusive SDM model and the competence model is that the former acknowledges the contextual and interpersonal nature of decision-making processes, whereas the latter defines DMC as a property of individual persons. But this is not so. As we show in the following section, the competence model can incorporate SDM and accommodate contextual and interpersonal features of decision-making processes. The main difference between the two models is rather that on the competence model there is a separate question as to whether SDM enables the supported person to understand and appreciate the nature and implications of the treatment choice at hand. Where support proves to be sufficient, the supported person retains legal capacity and she will be in the position either to endorse or to challenge the actions of support persons; and where support proves to be insufficient, the competence model formally delegates final decision-making authority to the substitute decision-maker. This enables the medical staff to identify conflicts of interest and detect possible abuse, and allows for the development of legal procedures that enable patients and third parties to challenge the actions of support persons and substitute decision-makers. In many jurisdictions solid procedures are in place.

It is different with the exclusive SDM model. On this model, the support person has the authority to interpret the current wishes and preferences of the supported person and derive treatment choices from them. ${ }^{38}$ Since on the exclusive SDM model the supported person retains legal capacity under this arrangement, treatment choices derived by the support person will count as treatment choices made by the supported person. There can accordingly be no separate question as to whether the supported person endorses the decisions of the support person. The Committee recognises that 'health and medical personnel should ensure[...], to the best of their ability, that assistants or support persons do not substitute or have undue influence over the decisions of persons with disabilities' and notes that there must be 'a mechanism for third parties to challenge the action of a support person if they believe that the support person is not acting in accordance with the will and preferences of the person concerned'. ${ }^{3}$ Unfortunately, the Committee does not provide us with any clue as to how the actions of support persons could be monitored and challenged. We believe that doing so will be extremely complicated on the exclusive SDM model. It will be more difficult for the medical staff to monitor the actions of support persons because the distinction between the interests of the patient and those of the support person becomes diffuse. And it will become more difficult to challenge the actions of support persons before court because any treatment decision made will not count as the decision of the support person on behalf of the patient but as the decision of the patient.

A fourth and related problem is that the exclusive SDM model seriously complicates the distribution of responsibility for treatment decisions. We first note that our argument does not rely on any particular theory of responsibility. Rather, we depart from the basic fact that by exercising one's legal capacity one assumes responsibility for certain outcomes and thereby absolves others from responsibility for those outcomes. By signing a consent form, for example, one waives the right to sue the treating physician in case one incurs a damage (eg, bleeding) as a consequence of the intervention, as long as the risk of this outcome was adequately disclosed and the damage was not due to negligence on the part of the treatment team. Every exercise of legal capacity thus entails a specific distribution of responsibility.

On the competence model, responsibility for treatment decisions along with their possible negative consequences can be 
distributed neatly to individuals: if the patient is competent, she has decision-making authority and bears responsibility for the decision taken; if she is incompetent, final decision-making authority and responsibility for the treatment decision lie with the substitute decision-maker.

On the exclusive SDM model, by contrast, decision-making authority and responsibility for treatment decisions lie with the patient regardless of her level of DMC. No matter how much support a patient may have received from others, the treatment decision remains an exercise of her own legal agency. And that means that the patient will bear full responsibility for the treatment decision along with its consequences. This distribution of responsibility seems first of all unfair in view of the process by which the decision came about. But even setting aside issues of fairness, a scheme that distributes responsibility exclusively to the patient leaves support persons without accountability. And by failing to provide proper checks and balances for support persons, the exclusive SDM model increases the risk of abuse.

A proponent of the exclusive SDM model may at this point suggest that responsibility for decision-outcomes can be distributed among patient and support persons in a way that reflects their respective contributions to the decision-making process. This is an interesting proposal, but we are unconvinced that it is able to solve the problem at hand. First, given the close connection between responsibility and legal capacity indicated above, the proposal seems to entail that legal capacity should likewise be distributed among the individuals involved in the decision-making process. But this would be incompatible with the exclusive SDM model. After all, an essential feature of this model is that supported persons retain full legal capacity. Second, recent philosophical debates on collective responsibility suggest that it is often very hard and sometimes impossible to distribute responsibility for the outcomes of collective decision-making processes to the individuals involved in the process. ${ }^{27}$ In view of this, it is doubtful whether the proposal could be implemented in practice.

A fifth complication concerns the allocation of decision-support. Providing decision-support is time-consuming. Since time resources are scarce among health professionals and among relatives and friends, it is necessary to specify criteria for an efficient and fair allocation of decision-support. Competence assessments provide particularly clear criteria. On the competence model, decision-support is called for when a person's DMC is below the threshold at which she can be accorded decision-making authority. Note that this does not mean that persons who are in need of support will be deemed incompetent. The reason is that decision-support may have the effect of raising the person's DMC above the relevant threshold. In this way, the competence model also provides a success criterion for decision-support: it is successful when it raises a patient's DMC beyond the relevant threshold. Finally, the competence model entails that support is not necessary in the first place when a patient's DMC is already above the threshold (although support may of course be helpful in such cases). In this way, competence assessments protect patients from undue influence exerted by relatives or friends. "Sorry Mr. X, but your mother can decide for herself," is a phrase that is and should be heard in hospitals.

Bach and Kerzner similarly propose to allocate decision-support on the basis of a 'functional assessment of decision-making capability', yet in keeping with their SDM model they immediately add the caveat that this assessment 'is not used to determine whether or not a person has legal capacity, but rather the status (ie, legally independent or supported decision-making status) through which they will exercise it'. ${ }^{8}$ This proposal sounds paradoxical, for by saying that a person is accorded legally independent status on the basis of an assessment of DMC, Bach and Kerzner seem to concede what they intend to deny, namely that a person's level of DMC determines whether a person has the right to make her own treatment decisions.

Maybe it is for this reason that the Committee explicitly rejects this method of allocating decision-support. 'The provision of support to exercise legal capacity should not hinge on mental capacity assessments', it asserts and proceeds to note that 'new, non-discriminatory indicators of support needs are required in the provision of support to exercise legal capacity'. ${ }^{3}$ Again, the Committee does not provide us with any indication whatsoever as to what these non-discriminatory indicators could be. And there seems to be an obvious reason for this silence. Since the aim of SDM is to support a person in making treatment decisions, it is hard to imagine what could serve as the criterion for the allocation of decision-support except for the person's level of DMC.

A sixth and final adverse consequence of the CRPD for persons with mental disabilities is that article 12 seriously limits the possibilities of advance care planning. Interestingly, the Committee claims that 'all persons with disabilities have the right to engage in advance planning and should be given the opportunity to do so on an equal basis with others'. ${ }^{3}$ Advance directives are the most important instruments for advance care planning. The problem is that advance care planning in general and advance directives in particular depend on a notion of competence. Indeed, it is precisely the point of advance directives that a person's treatment preferences when competent should override her preferences when incompetent.

If it is impermissible to deny persons the right to make treatment decisions on the basis of impaired DMC, health professionals must discard advance directives whenever they conflict with the current wishes and preferences of their patients, that is, whenever they could be useful. While the Committee acknowledges that 'to plan in advance is an important form of support', it immediately proceeds to explain that advance care planning enables persons to 'state their will and preferences which should be followed at a time when they may not be in a position to communicate their wishes to others'. ${ }^{3}$ By making this qualification, the Committee seems to limit the use of advance care planning and advance directives to situations in which persons are unconscious, as when they are in a comatose or vegetative state. The chance that one will get into a comatose or vegetative state is very small; and if one happens to get in such a state, most probably this was impossible to anticipate. The CRPD thus reduces the opportunities for persons with mental disabilities to engage in advance care planning to a minimum.

\section{A COMBINED MODEL: DECISION-SUPPORT AND COMPETENCE ASSESSMENT}

The adverse consequences that we have identified can be averted by adopting an alternative model of SDM. The Committee sees substitute decision-making and SDM as two mutually exclusive 'paradigms', where the former paradigm should be abolished and replaced by the latter. In contrast to this exclusive SDM model, we propose to combine the strengths of the competence model and SDM. On this combined SDM model, decision-support must be provided with three aims. It must be provided (1) to enhance a person's DMC, (2) to improve advance care planning and (3) to improve substitute decision-making. In this section, we will sketch the outlines of the combined SDM model. 
As we noted earlier, the nature of the competence model varies depending on how the criteria for competence are spelled out. We adopt a functional approach to competence, as opposed to a status or an outcome approach. Where the status approach defines incompetence in terms of diagnostic categories or the presence of a mental disorder, the outcome approach defines it in terms of the substantial irrationality of treatment decisions. ${ }^{3}$ By contrast, the functional approach defines incompetence in terms of a substantial impairment of functional and psychological capacities related to decision-making, DMC for short. ${ }^{28}$

A widely accepted version of the functional approach is the account of competence proposed by Grisso and Appelbaum. On this account, a person is competent to make a particular treatment decision if, and only if, she is sufficiently able to express a treatment choice, to understand the information relevant to making the treatment choice, to appreciate that the information applies to her condition and to process the information in a rational way. ${ }^{29} 30$ The MacArthur Competence Assessment Tool for Treatment (MacCAT-T) is a clinical tool that operationalises these criteria, and studies have shown that by using this tool a high level of inter-rater agreement among capacity evaluators can be reached. ${ }^{31}$ Modest schooling of health professionals can accordingly ensure that the criteria for competence are applied in a non-arbitrary way. ${ }^{32}$

An important feature of the functional approach is that on this approach the criteria for competence apply indiscriminately to all persons, regardless of whether they have a mental disability. It is furthermore generally accepted that on the functional approach determinations of incompetence are task-specific and time-indexed. Note that the task-specific and time-indexed nature of competence does not contradict the conceptions of autonomy and well-being that we have postulated in the previous section. After all, it makes perfect sense to say that competence assessments determine whether at this point of time a person is able to judge whether this particular treatment is conducive to her long-term well-being and consistent with her overall conception of the good.

Elsewhere, we argue that a competence model based on the functional approach does not discriminate against persons with mental disabilities (Scholten M, Gather J, Vollmann J. Competence to consent, substitute decision-making, and discrimination of persons with mental disabilities. Submitted for publication). Here, we will therefore assume that this model is compatible with the CRPD's principal aims of securing equal treatment and counteracting discrimination of persons with mental disabilities.

We propose to combine this version of the competence model with the SDM model. In our view, states and health professionals have a positive duty to provide decision-support to persons with impaired DMC. This duty can be seen as deriving from the demand for reasonable accommodation present in human rights documents. Article 2 CRPD defines reasonable accommodation as 'necessary and appropriate modification and adjustments not imposing a disproportionate or undue burden, where needed in a particular case, to ensure to persons with disabilities the enjoyment or exercise on an equal basis with others of all human rights and fundamental freedoms'. ${ }^{16}$ Since CRPD article 2 counts denial of reasonable accommodation as discrimination on the basis of ability, CRPD article 5 asserts that state parties have an obligation 'to take all appropriate steps to ensure that reasonable accommodation is provided'. ${ }^{16}$ At present, only a few countries have provisions for supported decision-making. ${ }^{33}$

The first type of decision-support should be provided before recourse to substituted decision-making is taken. The aim of this type of support is to enhance the DMC of patients, ideally up to a point where substitute decision-making becomes superfluous. While it is widely accepted that medical health professionals have a positive obligation to create circumstances in which their patients are able to give informed consent, this duty is typically thought to apply only to the aspects of disclosure, voluntariness and consent: health professionals have a positive obligation to disclose the relevant information adequately, to remove any form of undue influence and to give the patient the opportunity to accept or refuse the proposed treatment explicitly. We argue that this positive obligation also applies to competence.

Since people are inclined to think of psychological capacities as inherent properties of persons, it may seem as if health professionals cannot influence a patient's DMC. On reflection, however, DMC depends as much on situational as on mental factors and that means that health professionals can enhance their patients' DMC by influencing situational factors. The empirical basis for the effectiveness of decision-support broadly conceived is still meagre, ${ }^{24}{ }^{25}$ but various studies have shown that relatively simple interventions can significantly enhance the DMC of persons with schizophrenia, bipolar disorder or mild forms of dementia. ${ }^{34}$

Enhancement methods range from prosaic interventions to more advanced tools for decision-support. Health professionals can support their patients' DMC by influencing situational factors or changing their communication strategies, for example, by providing for a safe and calm environment, giving the patient time to adapt after admission to hospital, using plain language or illustrations or facilitating support by peers, relatives or friends. Health professionals can furthermore enhance their patients' DMC by medical means (provided that the patient is competent to consent to the intervention), for instance, by reducing or avoiding anticholinergic or sedative medications or by treating underlying medical conditions that may temporarily reduce one's decision-making capabilities, such as electrolyte disturbances, dehydration or infections. ${ }^{35}$

Notwithstanding its promise, SDM has its limits. Undeniably, there are situations where despite the decision-support offered, a patient remains unable to make an informed treatment decision. The comatose patient provides a pertinent example, but similar considerations hold for a range of persons with other conditions, such as late stage dementia or psychosis. Accordingly, SDM does not make competence assessment and substitute decision-making superfluous. That said, reasonable accommodation requires health professionals to exhaust the available resources of SDM before they take recourse to substitute decision-making.

The second and third types of decision-support serve to improve the process of substitute decision-making. The aim of the second type is to improve the process of advance care planning. First, scholars and clinicians have the task to further develop and make available a variety of tools for advance care planning, such as advance directives, psychiatric advance directives, joint crisis plans, crisis cards and self-binding directives. Policy makers should adopt explicit regulations that make such tools legally binding. The aim of developing a variety of tools is to ensure that every person has access to a tool that is tailored to his or her particular needs. Second, health professionals should facilitate the process of advance care planning. Completing an advance directive in such a way that it contains useful information to guide future medical decision-making is a difficult task. Health professionals should therefore inform persons who want to complete an advance directive about the possible pitfalls and about the expected benefits and burdens of the various treatment options. Studies show that the number and quality of advance directives can be increased and 
improved through assistance by specially trained personnel or peer trainers. ${ }^{36}$

The third type of decision-support serves to improve the accuracy of substitute decisions. Several empirical studies have shown that the accuracy by which substitute decision-makers predict the treatment preferences of patients is low, namely around $68 \% .^{37}$ To some this may seem a decisive argument against the practice of substitute decision-making, but we believe that it is not. First, the accuracy of substitute decisions should be compared with the possible alternatives, and as we have shown in the previous section, the exclusive SDM model is not expected to do better in this respect. Second, despite the inaccuracy of a part of substitute decisions, a study shows that $83 \%$ of patients whose treatment preferences were overridden when incompetent approved of the received treatment in retrospect. ${ }^{38}$ Third, it would seem that the accuracy of substitute decisions can be increased by providing substitute decision-makers with the necessary support. This brings us to the third type of decision-support.

Support to substitute decision-makers can take various forms. When incompetence is expected to occur in the course of the patient's disorder, opportunities should be created for substitute decision-makers to discuss treatment preferences with the patient. This will improve the substitute decision-maker's ability to abide by the patient's previously expressed treatment wishes in situations in which the patient is incompetent. Substitute decision-makers should additionally be educated regarding the substituted judgement and the best interest standard. For example, substitute decision-makers should be told to take heed not to base a treatment decision on what they themselves would want if they were in the patient's situation, but rather on what the patient would want if she were competent.

Additionally, substitute decision-makers should be made aware of the fact that persons with impaired DMC have an interest in making their own decisions. Although treatment choices of persons with substantially impaired DMC do not count as an exercise of legal agency, they should nevertheless be given weight in deliberations leading up to substitute decisions. For this reason, incompetent persons should be involved in the decision-making process as far as possible. Here, too, educative interventions can improve substitute decision-making. On the one hand, substitute decision-makers must be made aware of the risk of misinterpreting involuntary as meaningful behaviour. Persons with severe brain disorders or severe organic psychiatric disorders may for instance show automatic behaviour that is unrelated to preferences or emotional states. On the other hand, substitute decision-makers should be made aware of the risk of interpreting purposive and meaningful actions as behaviour without meaning. Accordingly, substitute decision-makers should genuinely engage with incompetent persons and they should be open and sensitive to unconventional communication styles.

\section{CONCLUSION}

In this article, we have identified six adverse consequences of CRPD article 12 for persons with mental disabilities and proposed an alternative way forward. While we believe that this alternative way forward is compatible with the CRPD's principle aims of promoting the autonomy, ensuring equal treatment and counteracting discrimination of persons with mental disabilities, it is not compatible with the provisions of article 12 .

One could be tempted to think that the latter point is mitigated by the following considerations. On ratification of the CRPD, countries such as Australia, Canada, France, the Netherlands and Norway expressed reservations regarding article 12, declaring their understanding that the article allows for substituted decision-making. This means that the legal effect of article 12 is modified accordingly in the named countries. Similar considerations may hold for Germany. Recently, the Federal Constitutional Court of Germany declared that denying an incompetent person the right to make treatment decisions does not violate article 12 of the CRPD. ${ }^{39}$

We think that this kind of legal gymnastics is unhelpful. Firstly, this strategy is likely to preserve the status quo and obstruct processes that might lead to legal reform. Secondly, human rights documents do not only exert legal force; they also make a moral appeal. Since the Committee has the right to comment publicly on the reports of states parties, conscientious and committed health professionals who do everything in their power to provide adequate care and who in doing so comply with their local jurisdictions will be communicated that they are complicit in human right violations; and this is unhealthy for the profession. For these reasons, we advise states parties that disagree with the Committee's General Comment and the UN High Commissioner's recent report to express their disagreement explicitly. We note that in accordance with CRPD article 47 , it is possible to propose amendments to the convention. The combined SDM model that we have outlined in this article could serve as a template for an amendment of CRPD article 12.

Acknowledgements The authors would like to thank Jochen Vollmann for helpful suggestions and two anonymous referees for Journal of Medical Ethics for their helpful comments on an earlier version of this paper.

Contributors Both authors made substantial contributions to the conception and design of the work. MS drafted the work and JG revised it critically for important intellectual content. Both authors agreed with the argument and conclusions of the work and gave final approval of the version to be published.

Funding This research is part of the international and interdisciplinary project ENSURE (2016-2019) and is supported by a grant from the German Federal Ministry of Education and Research (grant number 01GP1623B).

Competing interests None declared.

Provenance and peer review Not commissioned; externally peer reviewed.

Open Access This is an Open Access article distributed in accordance with the Creative Commons Attribution Non Commercial (CC BY-NC 4.0) license, which permits others to distribute, remix, adapt, build upon this work non-commercially, and license their derivative works on different terms, provided the original work is properly cited and the use is non-commercial. See: http://creativecommons.org/ licenses/by-nc/4.0/

(c) Article author(s) (or their employer(s) unless otherwise stated in the text of the article) 2018. All rights reserved. No commercial use is permitted unless otherwise expressly granted.

\section{REFERENCES}

1 United Nations, Treaty Collection. Convention on the Rights of Persons with Disabilities. Human rights. https://treaties.un.org/pages/ViewDetails.aspx?src= TREATY\&mtdsg_no=IV-15\&chapter=4\&clang=_en (accessed 7 Jun 2016).

2 United Nations High Commissioner for Human Rights. Mental health and human rights. https://documents-dds-ny.un.org/doc/UNDOC/GEN/G17/021/32/PDF/ G1702132.pdf?OpenElement (accessed 9 Apr 2017).

3 Committee on the Rights of Persons with Disabilities. General comment no. 1: Article 12: equality before the law. http://tbinternet.ohchr.org/_layouts/treatybodyexternal/ Download.aspx?symbolno=CRPD/C/GC/1\&Lang=en (accessed 1 Jun 2016).

4 Minkowitz T. Abolishing mental health laws to comply with the Convention of the Rights of Persons with Disabilities. In: McSherry B, Weller P, eds. Rethinking rightsbased mental health laws. Hart: Oxford, 2010:151-77.

5 Arstein Kerslake A, Flynn E. The right to legal agency: domination, disability and the protections of Article 12 of the Convention on the rights of persons with disabilities. Int J Law Context 2017:13:22-38.

6 Freeman MC, Kolappa K, de Almeida JM, et al. Reversing hard won victories in the name of human rights: a critique of the general comment on article 12 of 
the UN convention on the rights of persons with disabilities. Lancet Psychiatry 2015:2:844-50.

7 Appelbaum PS. Protecting the rights of persons with disabilities: an international convention and its problems. Psychiatr Serv 2016;67:366-8.

8 Bach M, Kerzner L. A new paradigm for protecting autonomy and the right to legal capacity. https://www.lco-cdo.org/wp-content/uploads/2010/11/disabilitiescommissioned-paper-bach-kerzner.pdf (accessed 7 Jun 2016).

9 Chartres D, Brayley J. Office of the Public Advocate South Australia: submission to the productivity commission inquiry into disability care and support. http://www.pc.gov.au/ inquiries/completed/disability-support/submissions/sub0325.pdf (accessed 7 Jun 2016).

10 Bartlett P. The United nations convention on the rights of persons with disabilities and mental health law. Mod Law Rev 2012;75:752-78.

11 Richardson G. Mental disabilities and the law: from substitute to supported decisionmaking? Curr Leg Probl 2012;65:333-54.

12 Burch M, Michalowski S, Jutten T, et al. Achieving CRPD compliance. http://autonomy. essex.ac.uk/uncrpd-report (accessed 24 Oct 2016).

13 McSherry B, Wilson K. The concept of capacity in Australian mental health law reform: going in the wrong direction? Int I Law Psychiatry 2015:40:60-9.

14 Szmukler G, Bach M. Mental health disabilities and human rights protections. Glob Ment Health 2015;2:1-9.

15 Ward A, Keene AR, Hempsey A, et al. Three jurisdictions report: towards compliance with CRPD Art. 12 in capacity/incapacity legislation across the UK. https://autonomy. essex.ac.uk/wp-content/uploads/2017/01/EAP-3J-Final-Report-2016.pdf (accessed 30 Mar 2017).

16 United Nations. Convention on the Rights of Persons with Disabilities and Optional Protocol, 2006. http://www.un.org/disabilities/documents/convention/convoptprot-e. pdf (accessed 1 Jun 2016).

17 Dinerstein R. Implementing legal capacity under article 12 of the UN convention on the rights of persons with disabilities: the difficult road from guardianship to supported decision-making. Human Rights Brief 2012;19:1-5.

18 Degener T. Editor's foreword. Int J Law Context 2017:13:1-5.

19 Szmukler G, Daw R, Callard F. Mental health law and the UN convention on the rights of persons with disabilities. Int J Law Psychiatry 2014;37:245-52.

20 Dawson J. A realistic approach to assessing mental health laws' compliance with the UNCRPD. Int I Law Psychiatry 2015;40:70-9.

21 Beauchamp TL, Childress JF. Principles of biomedical ethics. 7th ed. Oxford: Oxford University Press, 2013.

22 Buchanan AE, Brock DW. Deciding for others: the ethics of surrogate decision making. Cambridge: Cambridge University Press, 1990
23 Division for Pocial Policy and Development Disability. Committee on the rights of persons with disabilities. http://tbinternet.ohchr.org/_layouts/ treatybodyexternal/ TBSearch.aspx? Lang=en\&TreatyID=4\&DocTypelD=5 (accessed 7 Jun 2016).

24 Kohn NA, Blumenthal JA, Campbell T. Supported decision-making: a viable alternative to guardianship? Penn St L Rev 2013;117:1111-57.

25 Kohn NA, Blumenthal JA. A critical assessment of supported decision-making for persons aging with intellectual disabilities. Disabil Health J 2014;7:S40-S43.

26 Craigie J. A fine balance: reconsidering patient autonomy in light of the UN convention on the rights of persons with disabilities. Bioethics 2015;29:398-405

27 Pettit P. Responsibility incorporated. Ethics 2007;117:171-201.

28 Grisso T. Evaluating competencies: forensic assessments and instruments. 2nd ed. New York: Kluwer Academic Publishers, 2003.

29 Grisso T, Appelbaum PS. Assessing competence to consent to treatment: a guide for physicians and other health professionals. Oxford: Oxford University Press, 1998.

30 Appelbaum PS. Clinical practice. Assessment of patients' competence to consent to treatment. N Engl J Med 2007;357:1834-40.

31 Cairns R, Maddock C, Buchanan A, et al. Reliability of mental capacity assessments in psychiatric in-patients. Br J Psychiatry 2005;187:372-8.

32 Raymont V, Buchanan A, David AS, et al. The inter-rater reliability of mental capacity assessments. Int I Law Psychiatry 2007;30:112-7.

33 Pathare S, Shields LS. Supported decision-making for persons with mental illness: a review. Public Health Rev 2012;34.

34 Nishimura A, Carey J, Erwin PJ, et al. Improving understanding in the research informed consent process: a systematic review of 54 interventions tested in randomized control trials. BMC Med Ethics 2013;14:28.

35 Appelbaum PS. Consent in impaired populations. Curr Neurol Neurosci Rep 2010;10:367-73

36 Swanson JW, Swartz MS, Elbogen EB, et al. Facilitated psychiatric advance directives: a randomized trial of an intervention to foster advance treatment planning among persons with severe mental illness. Am J Psychiatry 2006; 163:1943-51.

37 Shalowitz DI, Garrett-Mayer E, Wendler D. The accuracy of surrogate decision makers: a systematic review. Arch Intern Med 2006;166:493-7.

38 Owen GS, David AS, Hayward P, et al. Retrospective views of psychiatric in-patients regaining mental capacity. Br J Psychiatry 2009;195:403-7.

39 Federal Constitutional Court of Germany. Beschluss. 2016 https://www. bundesverfassungsgericht.de/SharedDocs/Entscheidungen/DE/2016/07/Is20160726_ 1bvl000815.html (accessed 9 Apr 2017). 